\title{
Thiadiazole-induced Myelodysplasia in Rats ${ }^{1}$
}

\author{
ALLAN R. BEAUDOIN \\ Department of Anatomy, The University of Michigan, Ann Arbor, \\ Michigan 48104
}

\begin{abstract}
Pregnant Wistar rats were injected ip with a teratogenic dose (100 $\mathrm{mg} / \mathrm{kg}$ ) of 2-amino-1,3,4-thiadiazole hydrochloride (ATDA) on day 11 of gestation (sperm day $=$ day 0 ). Pregnancy was terminated at various intervals following drug injection. At autopsy some embryos were dead, some severely affected, and others only mildly affected by the treatment. The neural tube was more sensitive to ATDA than was any other tissue. The first histologically observable effect of maternal ATDA treatment was embryonic cell death in the caudal end of the neural tube, $12 \mathrm{~h}$ after treatment. During the next $24 \mathrm{~h}$ additional cells in the neural tube died, as well as cells in associated ganglia and in areas of condensing mesenchyme and somites. The tissues of the tail were especially sensitive to ATDA treatment. Forty-eight hours after treatment repair and regeneration of neural tissue was evident. At day 20, spinal cords of affected fetuses had excrescences growing from the luminal wall, rosettes, duplication of the central canal, premature termination, and disruption of normal cellular patterns. Fetuses with myelodysplasia also had short or absent tails. It is postulated that malformations resulting from maternal ATDA treatment are due to cell death caused by ATDA acting directly on embryonic cells, with the ultimate outcome depending on the number of mitotically active cells that survive treatment to continue the process of organogenesis.
\end{abstract}

Myelodysplasias in animals have been reported to occur spontaneously and to follow a variety of experimental treatments (for review of literature see Kalter, '68). The array of developmental defects ranges from duplications of the central canal to myeloschisis.

Recently it was reported that treatment of pregnant rats with 2-amino-1,3,4-thiadiazole hydrochloride produced a high incidence of neural-tube defects (Beaudoin, '71, '73). The present investigation was undertaken to analyze the time of onset and the nature of thiadiazole-induced neural-tube damage.

\section{MATERIALS AND METHODS}

Virgin female Wistar-derived rats from our colony were used. The animals were maintained on a Rockland Complete Rat Diet ad libitum, with supplemental feedings of lettuce. Day 0 of pregnancy was considered to begin on the morning sperm were found in the vaginal smear. 2-Amino1,3,4-thiadiazole hydrochloride (ATDA) was administered as a $2 \%$ aqueous solution ip, at $10 \mathrm{AM}$ on day 11 of gestation, $100 \mathrm{mg} / \mathrm{kg}$ maternal body weight. Preg- nancy was terminated at different intervals following injection, as indicated below, and the offspring were recovered and fixed in Bouin's fluid. Offspring were serially sectioned at 7 or $10 \mu$ and stained with either Ehrlich's acid hematoxylin and light green or Harris' HE. Offspring from treated rats were compared with offspring of the same age from untreated rats.

\section{RESULTS}

Treatment of pregnant rats with ATDA on day 11 of gestation produced diverse effects on the offspring. At autopsy some were dead, others severely affected (surely some would have died in utero), and some only mildly affected. Generalized growth retardation was noted in all surviving offspring. The neural tube showed a wide range in severity of damage; however in all offspring examined the caudal segments of the neural tube were much more susceptible to the effects of ATDA treatment than any other part.

\footnotetext{
Received July 10, '73. Accepted Oct. 10, '73.

1 Supported by NIH grant HD00400.
} 
TABLE 1

Prenatal mortality following $100 \mathrm{mg} / \mathrm{kg}$ thiadiazole injection at day 11 of gestation

\begin{tabular}{ccc}
$\begin{array}{c}\text { Day of } \\
\text { embryo } \\
\text { recovery }\end{array}$ & $\begin{array}{c}\text { No. of } \\
\text { implantation } \\
\text { sites }\end{array}$ & $\begin{array}{c}\% \\
\text { resorbed }\end{array}$ \\
\hline 11 & 32 & 0 \\
12 & 53 & 0 \\
13 & 71 & 15.5 \\
14 & 43 & 25.6 \\
15 & 58 & 46.9 \\
201 & 270 & 37.5 \\
\hline
\end{tabular}

1 From Beaudoin ('73).

The initial histologically observable effect following maternal ATDA treatment was embryonic cell death. Necrotic cells were not limited to the neural tube but were also observed in other areas of the embryo as well, as noted below. A detailed study of embryolethality and malformations caused by ATDA imjection has already been reported (Beaudoin, '73). The timing and extent of prenatal death are given in table 1 . The following discussion will emphasize the effects on the developing neuraxis.

$6 h$ postinjection. Eleven embryos from three litters were examined. There were no observable effects of treatment at this time.

$12 h$ postinjection. Four of five embryos examined exhibited cell necrosis, limited to the neural tube in the tail bud. The integrity of the neural-tube lining was lost and cells and cellular debris appeared in the lumen (figs. 1, 2).

$24 h$ postinjection. Eleven embryos from four litters were examined. One embryo was dead. The remaining all exhibited evidence of damage to the neural tube. Necrotic cells were scattered in the mantle layer throughout the length of the neural tube. Mitoses were common in the ependymal zone. In the brain region of some embryos circumscribed areas were found in which the internal limiting membrane had broken down and cells were found in the brain ventricles. At the level of the pharynx there were scattered necrotic cells in the spinal cord. At midbody level dead cells were more numerous in the basalplate zone than in the alar-plate zone. The most extensive damage to the neural tube was found at the level of the hindlimb buds and caudad. Diffuse areas of breakdown of the internal limiting membrane were seen and the cord lumen was filled with cells and cellular debris (figs. $3,4)$. In the tail region the lumen was absent and the cord completely disorganized (figs. 5, 6). Necrotic cells were also observed in cranial and spinal nerve ganglia, areas of condensing mesenchyme, and somites, especially those in the caudal body region. The notochord appeared normal except in the tail where it contained a few dead and dying cells. It is interesting to note that the notochord was the last tissue in the tail to show visible signs of ATDA treatment.

$48 \mathrm{~h}$ postinjection. Sixteen day-13 embryos from six litters were examined. Two were dead, three from a single litter had minimal neural-tube damage, and 11 , from five litters, had extensive damage to the neural tube. The most severely affected embryos had widespread cellular necrosis in the walls of the brain with cells, cellular debris, and blood present in the ventricular cavities (fig. 7). In less severely affected embryos necrotic cells were rare in the brain and the brainwall appeared quite normal. Dead cells were abundant in the spinal cords of the most severely affected embryos, and were again, as at $24 \mathrm{~h}$, more numerous in the basal plate zone. Many embryos had cells and cellular debris in the lumen of the spinal cord. Necrotic cells were rare in cords with minimal damage. The appearance of these cords gave evidence that repair of previous damage had taken place. Cellular excrescences were found grown into and often bridging the lumen (fig. 8). All embryos in the most severely affected group had markedly shortened tails. In these embryos the spinal cord was a mass of necrotic cells at the level of the hindlimb buds and caudad, similar to the day-12 cord illustrated in figure 4 . The surrounding tissue also showed extensive necrosis.

$72 h$ postinjection. Eleven day-14 embryos from two litters were examined. The brain and spinal cord had few if any dead cells. Repair of prior damage was evident. In all embryos examined the brain and upper levels of the spinal cord appeared essentially normal, although perhaps smaller than in the controls. These embryos were obviously not among those most drastically affected by the treatment (see 
$96 \mathrm{~h}$ below). The first evidence of spinal cord malformation was at the level of the hind limbs. In all cases examined the spinal cords were compressed dorsoventrally (rounder in appearance than in controls) and the lumina were partially occluded by cellular excrescences. All embryos had short tails (fig. 9).

$96 h$ postinjection. Nine day-15 embryos from three litters were examined. Seven presented essentially the same picture seen at $72 \mathrm{~h}$ posttreatment. These embryos had normal-appearing brains and upper spinal cords, but malformed lower cords. The first indication of spinal cord abnormality was observed at heart level in one embryo, at liver level in four embryos, and at the level of the hind limbs in two embryos. In all cases cellular excrescences projected into the central canal. The other two embryos had severe involvement of the brain and spinal cord with excrescences present in the diencephalon, mesencephalon, metencephalon, and myelencephalon. The numbers of such excrescences increased caudalward. The walls of the lateral ventricles were free of outgrowths. At the junction of the medulla and spinal cord the lumen was obliterated in one embryo but reopened further caudad. The cellular excrescences were observed in both embryos throughout the length of the cords, often growing across the lumen to unite with the opposite wall and in so doing created multiple lumina, suggesting the formation of rosettes (figs. 10-12). Both embryos had stub tails.

Day-20 fetuses. All day-20 fetuses were smaller than controls and many had malformations (Beaudoin, '73). Only the effects on the spinal cord will be reported here.

The spinal cords of 20 fetuses from nine litters were examined. One fetus had no external malformations, one appeared to have a short trunk, three exhibited hooked tails, seven had stub tails (less than $2 \mathrm{~mm}$ long) and eight were tailless. The fetuses without external malformations or with only misshapen tails had completely normal spinal cords. Six of the seven fetuses with stub tail, from three different litters, presented essentially the same picture of myelodysplasia. The central canal of the cord was occluded at or near the level of bifurcation of the trachea. The central canal remained occluded for various distances before reopening again. At times multiple canals were seen, giving a rosette appearance. The shape of the cord varied from normal to compressed dorsoventrally with the loss of the dorsal sulcus and the occurrence of a cluster of cells between the right and left dorsal columns (figs. $13,14)$. The histological picture of the cord changed from level to level. At the level of the cephalic pole of the kidneys the cord was essentially normal morphologically and histologically, but at the caudal level of the kidneys the cord began to terminate prematurely. The dorsal columns lost their identity and the cells disappeared. The remaining dorsal white matter was pinched off from the ventral cord and was lost (fig. 15). The cells remaining in the ventral cord region reorganized around a central canal and became fewer and fewer until at the level of the hip joint all that remained was a strand of nervous tissue (fig. 16). The vertebral neural arch was absent and posteriorly the strandlike cord became intermingled with skeletal muscle and connective tissue and disappeared. The seventh fetus, with stub tail, was more severely affected, presenting myeloschisis at kidney level. This cord subsequently terminated prematurely at the level of the hip joint.

The eight tailless fetuses presented the same array of myelodysplasias as the group of six stub-tail fetuses described above; all had prematurely terminating cords. In two fetuses there were normal neural arches despite the loss of the spinal cord from within the neural canal.

\section{DISCUSSION}

The teratogenic action of certain thiadiazoles in rats is well documented (Murphy et al., '57; Maren and Ellison, '72; Beaudoin, '71, '72, '73; Scott et al., '72). It has been suggested that cell death following thiadiazole treatment is causally related to the appearance of malformations in the limbs (Scott et al., '72, '73) and in the central nervous system (Beaudoin, '71).

The investigation reported here demonstrated the developing neuraxis to be particularly susceptible to the action of ATDA. The first observable histological effect was the appearance of necrotic cells 
in the caudal end of the embryonic neural tube $12 \mathrm{~h}$ after maternal treatment. With the passage of time more and more cells in the neural tube were affected as well as cells in associated ganglia, areas of condensing mesenchyme, and somites. The mesoderm of the caudal body region was more sensitive to the treatment than mesoderm elsewhere in the body. More resistant was the notochord which appeared to be the last tissue to show the effects of ATDA treatment. The appearance of the spinal cord just prior to birth (day-20 fetus) with excrescences, rosettes, duplications in the central canal, premature termination, and disruption of cellular patterns is strikingly similar to myelodysplasias illustrated in papers by Warkany and Takacs ('65) following treatment of rats with streptonigrin and by Warkany and Petering (72) following maternal zinc deficiency. Many types of myelodysplasias following various types of teratogenic treatment have been reported. The interested reader is referred to Kalter ('68).

Cell death per se has long been associated with the process of normal development of embryonic organs and tissues (e.g., urogenital system, central nervous system, developing limbs). In normal development cell death is usually associated with the removal of excess cells in the shaping of organs (see reviews by Glücksmann, '65; Saunders, '66). Cell death may accompany or precede congenital malformations (review by Menkes et al., '70). On the one hand it is easy to envision cell death contributing to the genesis of abnormalities because cell death disrupts the normal mitotic pattern of tissues and destroys cell contacts and cell movements vital to normal tissue interactions and inductive events. On the other hand it is known that malformations do not invariably follow cell death. Dead cells may be removed and replaced by mitotically active cells which subsequently reconstitute the tissue or organ. The resultant organ may be smaller but not anatomically malformed. The capacity for such regeneration is presumably limited by the total reduction in numbers of mitotically active cells and in the time remaining for organogenesis. Experimental evidence has shown this to be true in the embryonic central nervous system following $\mathrm{X}$ irradi- ation (Hicks et al., '57), in the developing eye after cobalt irradiation (Skalko, '65), and in embryonic limbs subsequent to maternal treatment with teratogens known to inhibit DNA synthesis (Scott et al., '71; Ritter et al., '73). Hicks et al. (57) reported damage sometimes ranged as high as half the cells yet recovery was possible and many times no abnormality resulted. The capacity of nervous tissue for repair and regeneration is confirmed in the present study. The ultimate outcome was apparently dependent on the number of mitotically active cells that survived treatment coupled with their ability to replace lost cells and continue the process of organogenesis. Various degrees of success were evident, more marked in cranial regions than in caudal regions of the neuraxis. The function of the nervous system was not evaluated in this study. However, Butcher et al. (73) have observed abnormal behavior, in the absence of overt CNS malformations, in offspring of hydroxyurea-treated pregnant rats. Hydroxyurea causes cell death in the embryonic neural tube.

The underlying cause of cell death following ATDA treatment is not known. The molecular weight of this drug (137.59) is such that it should be able to cross the placenta and act on the embryo directly (Moya and Thorndike, '62). At the time of treatment (day 11) the chorioallantoic placenta is becoming functional; in addition there is the recently completed yolksac placenta (Wilson et al., '59). However, this has no effect on the teratogenic outcome of the experiment, for ATDA has been demonstrated to be an effective teratogen from day 6 through 14 in rats (Beaudoin, '73). Supplemental treatment with nicotinamide effectively blocks the embryotoxic and teratogenic effects of the thiadiazoles (Beaudoin, '72, '73; Scott et al., '72). Since the usual fate of nicotinamide in the body is incorporation into nicotinamide adenine dinucleotide (NAD) or its phosphate (NADP) it is suggested that ATDA may interfere with the synthesis or utilization of $N A D(P)$ in cellular metabolism. A variety of teratogens have been reported to act by interfering with NAD(P) functions. The suggestion is that these nicotinamide-sensitive teratogens exert their effects by disrupting pathways 
of energy metabolism requisite for normal growth and development (Landauer and Wakasugi, '68; Caplan, '72). One consequence of disrupted energy metabolism could be cell death. ATDA has also been shown to depress embryonic DNA synthesis markedly (Scott et al., '72, '73). DeDuve (67) suggested that drugs may affect either the stability of lysosomal membranes or the rate of synthesis and secretion of the lysosomal enzymes. Release of lysosomal enzymes could contribute to the death of cells. An effect of ATDA on lysosomal function has not been reported.

It can be postulated that malformations resulting from maternal ATDA treatment are due to cell death caused by ATDA acting directly on embryonic cells. The caudal end of the neural tube and its surrounding tissues (except notochord) are particularly sensitive to ATDA treatment on day 11 of gestation. Questions still persist: what determines the differential susceptibility of cells to this treatment; does ATDA kill cells through its effect on NAD(P), DNA, or by some other means not yet detected?

\section{LITERATURE CITED}

Beaudoin, A. R. 1971 Teratogen-induced myelodysplasia and taillessness in the Wistar albino rat. Teratology, 4: 228 (abst.).

1972 Teratogenic action of 2-amino1,3,4-thiadiazole in rats. Teratology, 5: 250 (abst.).

1973 Teratogenic activity of 2-amino1,3,4-thiadiazole hydrochloride in Wistar rats and the protection afforded by nicotinamide. Teratology, 7: 65-72.

Butcher, R. E., W. J. Scott, K. Kazmaier and E. J. Ritter 1973 Postnatal effects in rats of prenatal treatment with hydroxyurea. Teratology, 7: 161-166.

Caplan, A. I, 1972 Comparison of the capacity of nicotinamide and nicotinic acid to relieve the effects of muscle and cartilage teratogens in developing chick embryos. Dev. Biol., 28: 344351 .

DeDuve, C. 1968 Lysosomes as targets for drugs. In: The Interaction of Drugs and Subcellular Components in Animal Cells. P. N. Campbell, ed. Churchill, London, pp. 155-169.
Glücksmann, A. 1965 Cell death in normal development. Arch. Biol, , 76: 419-437.

Hicks, S. P., B. L. Brown and C. J. D'Amato 1957 Regeneration and malformation in the nervous system, eye, and mesenchyme of the mammalian embryo after radiation injury. Am. J. Path., 33: 459-481.

Kalter, H. 1968 Teratology of the Central Nervous System. Univ. of Chicago, Chicago.

Landauer, W., and N. Wakasugi 1968 Teratological studies with sulphonamides and their implications. J. Embryol. Exp. Morph., 20: 261284.

Maren, T. H., and A. C. Ellison 1972 The teratological effect of certain thiadiazoles related to acetazolamide, with a note on sulfanilamide and thiazide diuretics. Johns Hopkins Med. J., 130: 95-104.

Menkes, B., S. Sandor and A. Ilies 1970 Cell death in teratogenesis. Adv. Terat., 4: 169-215.

Moys, F., and V. Thorndike 1962 Passage of drugs across the placenta. Am. J. Obst. Gynec., 84: 1778-1798.

Murphy, M. L., C. P. Dagg and D. A. Karnofsky 1957 Comparison of teratogenic chemicals in the rat and chick embryos. Pediatrics, 19: 701714.

Ritter, E. J., W. J. Scott and J. G. Wilson 1973 Relationship of temporal patterns of cell death and development to malformations in the rat limb. Possible mechanisms of teratogenesis with inhibitors of DNA synthesis. Teratology, 7: 219226.

Saunders, J. W. 1966 Death in embryonic systems. Science, 154: 604-612.

Scott, W. J., E. J. Ritter and J. G. Wilson 1971 DNA synthesis inhibition and cell death associated with hydroxyurea teratogenesis in rat embryos. Dev. Biol., 26: 306-315.

- 1973 DNA synthesis inhibition, cytoxicity and their relationship to teratogenesis following administration of a nicotinamide antagonist, aminothiadiazole, to pregnant rats. J. Embryol. Exp. Morph., 30: 257-266.

Scott, W. J,, J. G. Wilson and E. J. Ritter 1972 The teratogenic, biochemical and histological effects of aminothiadiazole and their reversibility by nicotinamide. Teratology, 5: 266 (abst.).

Skalko, R. G. 1965 The effect of $\mathrm{Co}^{60}$-radiation on development and DNA synthesis in the 11. day rat embryo. J. Exp. Zool., 160: 171-182.

Warkany, J., and H. G. Petering 1972 Congenital malformations of the central nervous system in rats produced by maternal zinc deficiency. Teratology, $5: 319-334$.

Warkany, J., and E. Takacs 1965 Congenital malformations in rats from streptonigrin. Arch. Path., 79: 65-79.

Wilson, J. G., A. R. Beaudoin and H. J. Free 1959 Studies on the mechanism of teratogenic action of trypan blue. Anat. Rec., 133: 115-128. 


\section{PLATE 1}

\section{EXPLANATION OF FIGURES}

1 Tail region of a normal day-11 embryo. $(\times 160)$

2 Tail region of a day-11 embryo from female that received ATDA $12 \mathrm{~h}$ earlier. Note the presence of necrotic cells in the wall and lumen of the neural tube. $(\times 160)$

3 Neural tube and surrounding tissue at the level of the posterior limb buds of a normal day-12 embryo. $(\times 100)$

4 Neural tube and surrounding tissue at the level of the posterior limb buds of a day-12 embryo from female that received ATDA $24 \mathrm{~h}$ earlier. There is extensive necrosis of cells in the neural tube, mesenchyme and somites. The neural tube lumen is filled with cells and cellular debris. $(\times 100)$

5 Tail region of a normal day-12 embryo. $(\times 150)$

6 Tail region of a day-12 embryo from female that received ATDA $24 \mathrm{~h}$ earlier. Note the absence of the neural tube and the presence of necrotic cells throughout the mesenchyme and notochord. $(\times 150)$ 

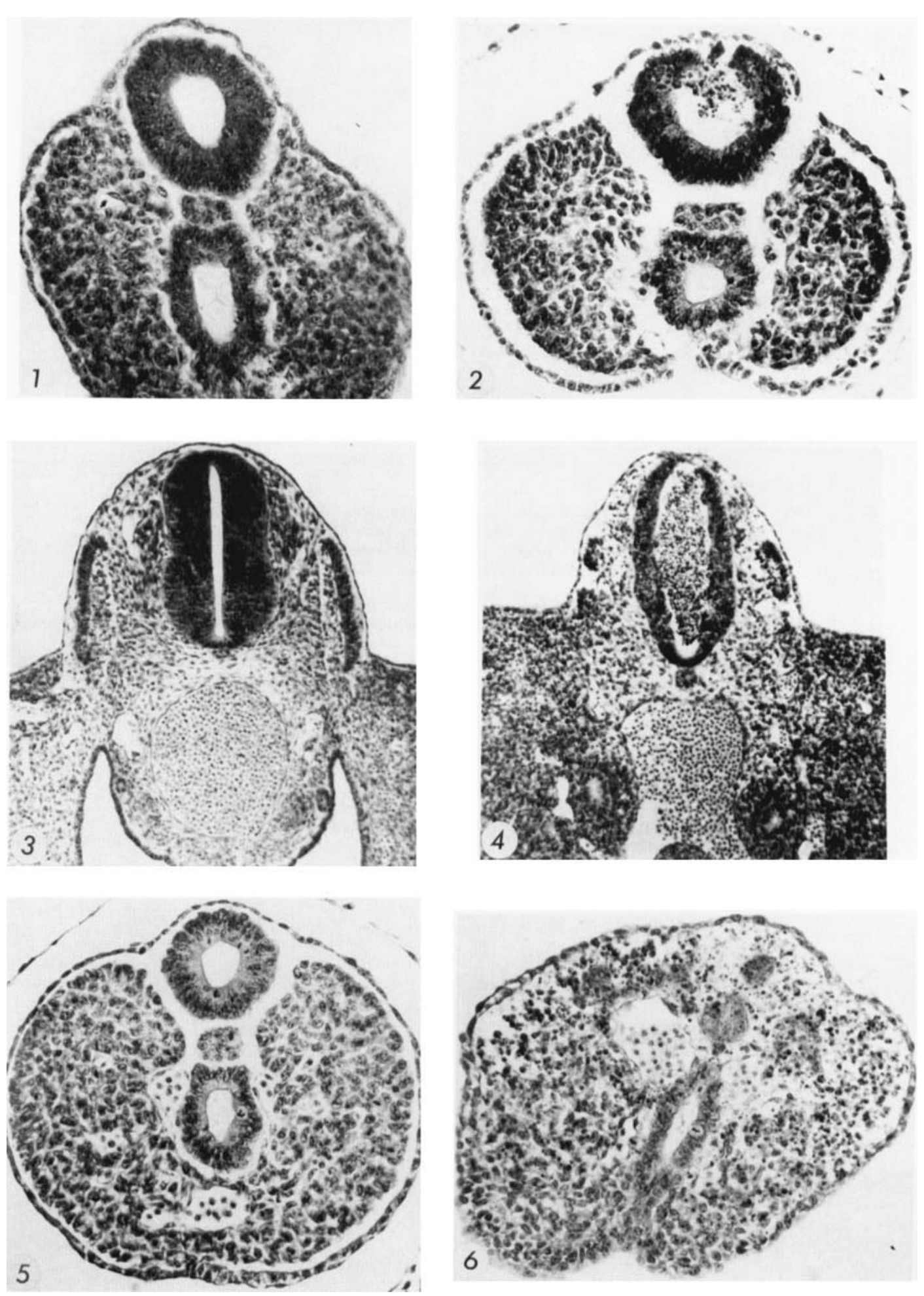
PLATE 2

\section{EXPLANATION OF FIGURES}

7 Section through diencephalon and myelencephalon of a day-13 embryo from female that received ATDA $48 \mathrm{~h}$ earlier. The brain ventricles contain cells, cellular debris, and blood. The brainwall shows evidence of loss of cells. $(\times 20)$

8 Neural tube at the hindlimb bud level of a day-13 embryo from female that received ATDA 48 h earlier. Note the paucity of necrotic cells and the cellular bridge across the lumen. This illustrates the first evidence of repair and regeneration. $(x 100)$

9 A control (left) and experimental (right) day-14 embryo. Note that the major part of the tail is missing in the embryo from female that received ATDA on day $11 .(\times 3)$.

10 Spinal cord at the hindlimb-bud level of a normal day-15 embryo. $(\times 60)$

11 Spinal cord at the hindlimb-bud level of a day-15 embryo from female that received ATDA $96 \mathrm{~h}$ earlier. Note the partitioning of the lumen by cellular excrescences. $(x 75)$

12 Spinal cord at the level of the liver in a day-15 embryo from female that received ATDA $96 \mathrm{~h}$ earlier. Note multiple lumina and appearance of rosettes. ( $\times 60)$ 

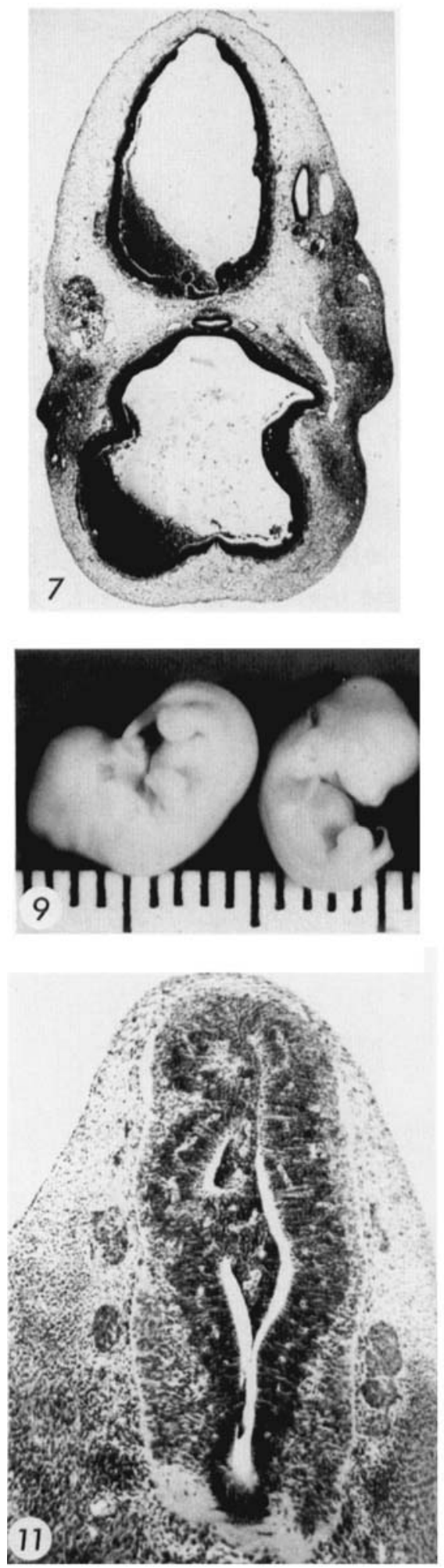
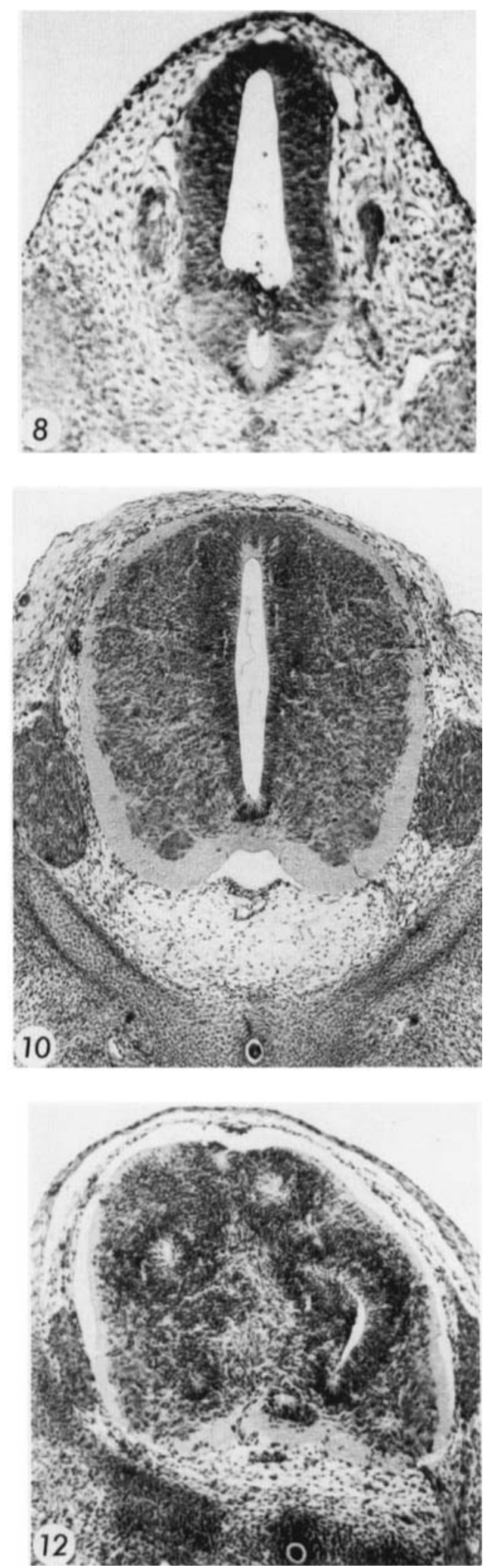
PLATE 3

EXPLANATION OF FIGURES

13 Spinal cord at kidney level of a normal day-20 fetus. $(\times 50)$

14 Spinal cord at kidney level from a day-20 fetus from female that received ATDA on day 11. Note the dorsovental compression of the cord with absence of the central canal and dorsal sulcus. A cluster of cells between the right and left dorsal columns. $(x 50)$

15 The same spinal cord as shown in figure 14, just caudal to the level of the kidney. The dorsal aspect of the cord appears to pinch off from the ventral aspect $(\times 50)$

16 The same spinal cord as shown in figures 14 and 15 , at the level of the hip joint. The arrow indicates all that remains of the cord. The vertebral neural arches are absent. $(\times 50)$ 

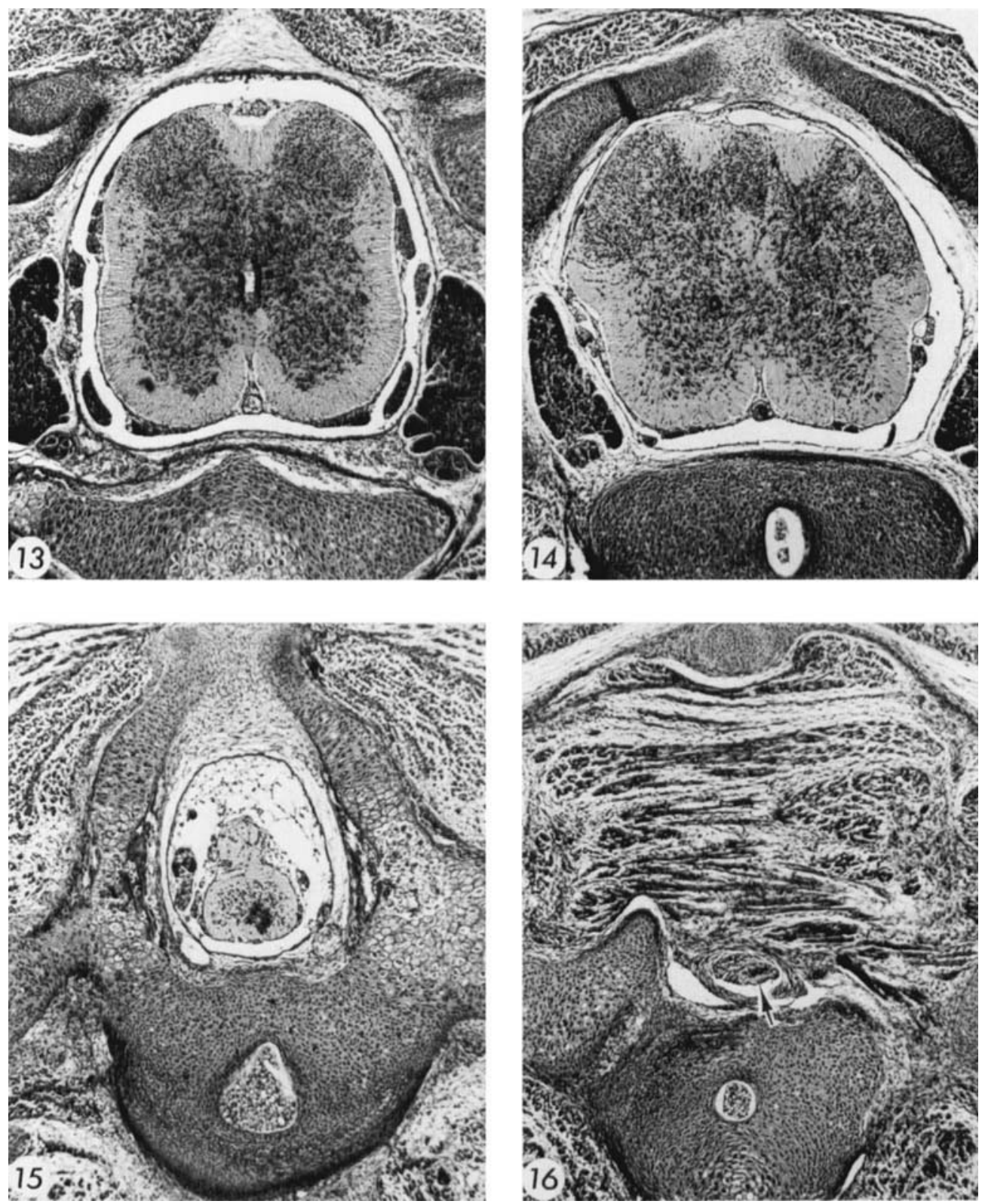